\title{
Wireless indoor network planning for advanced exposure and installation cost minimization
}

\author{
Ning Liu ${ }^{1,2}$, David Plets²* ${ }^{*}$ Kris Vanhecke ${ }^{2}$, Luc Martens ${ }^{2}$ and Wout Joseph ${ }^{2}$
}

\begin{abstract}
The possibility of having information access anytime and anywhere has caused a huge increase of the popularity of wireless networks. Requirements of users and owners have been ever-increasing. However, concerns about the potential health impact of exposure to radio frequency (RF) sources have arisen and are getting accounted for in wireless network planning. In addition to adequate coverage and reduced human exposure, the installation cost of the wireless network is also an important criterion in the planning process. In this paper, a hybrid algorithm is used to optimize indoor wireless network planning while satisfying three demands: maximum coverage, minimal full installation cost (cabling, cable gutters, drilling holes, labor, etc.), and minimal human exposure. For the first time, wireless indoor networks are being optimized based on these advanced and realistic conditions. The algorithm is investigated for three scenarios and for different configurations. The impact of different exposure requirements and cost scenarios is assessed.
\end{abstract}

Keywords: Indoor wireless network planning; Optimization algorithm; WiFi (IEEE 802.11n); Coverage; Installation cost and exposure

\section{Introduction}

Indoor wireless networks are playing a more and more important role in daily life due to the dramatically increasing amount of mobile devices. However, an adequate wireless network planning goes beyond providing a certain capacity to the users. A first significant characteristic of the designed network is the installation cost of, e.g., the wireless local area network (WLAN). Whereas current installation cost algorithms mainly look at the number of access points (APs) $[1,2]$, the full installation cost of a wireless network planning solution includes many more aspects, such as the cabling costs, the costs of drilling holes through walls, and labor costs for getting the APs connected to the power and data network [3]. Secondly, if planning tools account for exposure [4-6] (mostly not, such as [7-9]), they mostly limit or minimize electricfield strengths over the entire simulation area. In real life however, some rooms are more sensitive to high exposure

\footnotetext{
*Correspondence: david.plets@intec.ugent.be

${ }^{2}$ Ghent University/iMinds, Dept. of Information Technology, Gaston Crommenlaan 8 box 201, 9050 Gent, Belgium

Full list of author information is available at the end of the article
}

levels than others. For example, there are usually more people in office rooms than in kitchens or corridors and they also stay there for a longer time. Also, young children are more sensitive to exposure than adults. In daycare or in school buildings, rooms where many young children are present should preferably have lower exposure values. Therefore, this should be accounted for when planning wireless networks.

In this paper, for the first time, a cost optimization is performed that does not only look at merely the access point cost (see [10]) but at the total installation cost, which includes the cost of APs, infrastructure (cable gutters, cables, etc.), labor (working hours for installing APs and infrastructure), and other costs which are generated by installing process (such as drilling holes). It has been shown in [11] that the access point cost is only a fraction of the total cost, making the proposed cost optimization the most advanced and realistic one currently available. Furthermore, it is shown how the total human exposure can be minimized from a person-centric view, based on the sensitivity of the rooms to a high exposure value. These sensitivities are determined by the average number

\section{Springer}

(C) 2015 Liu et al. Open Access This article is distributed under the terms of the Creative Commons Attribution 4.0 International License (http://creativecommons.org/licenses/by/4.0), which permits unrestricted use, distribution, and reproduction in any medium, provided you give appropriate credit to the original author(s) and the source, provide a link to the Creative Commons license, and indicate if changes were made. The Creative Commons Public Domain Dedication waiver (http://creativecommons. org/publicdomain/zero/1.0/) applies to the data made available in this article, unless otherwise stated. 
of people present in the rooms and the person types (e.g., children vs. adults). To the authors' knowledge, this combination is now being investigated and realized for the first time. Thirdly, it is shown that also the optimization algorithm itself [10] is improved. The remainder of the paper is structured as follows.

In Section 2, related work is presented. Section 3 discusses the wireless configuration and Section 4 the optimization algorithm and the advanced fitness functions. In Section 5, three scenarios are introduced and they are simulated and discussed in Section 6. The influence of interference is discussed in Section 6.4. Finally, conclusions are presented in Section 7. Table 1 lists some abbreviations which are used in this paper.

\section{Related work}

Many researchers have worked on coverage and cost of wireless networks. Some of them focus on decreasing cost by using low-cost components of wireless networks $[12,13]$, by increasing utilization of equipment [14], or by decreasing energy consumption $[15,16]$. However, the complexity of the cost aspect has always been underestimated, e.g., in [17-19], the number of APs has been used to represent the network planning cost. In [20], the installation cost is accounted for, but it is considered constant and independent of the physical environment, while in reality the installation cost is much more complex than that. In [21], the cost of the infrastructure is considered, but the labor costs are ignored. In [22], an

Table 1 List of abbreviations

\begin{tabular}{cc}
\hline ACO & Ant colony optimization \\
AP & Access point \\
BFS & Breadth-first search \\
CDF & Cumulative distribution function \\
ECP & Ethernet connection point \\
EIRP & Equivalent isotropically radiated power \\
EMF & Electromagnetic field \\
ESL & Exposure sensitivity level \\
GA & Genetic algorithm \\
HIGO & Hybrid indoor genetic optimization \\
IM & Interference margin \\
LTE & Long-Term Evolution \\
RF & Radio frequency \\
RFID & Wuasi-particle swarm optimization \\
PCP & Simulated annealing \\
PSO & Padio frequency identification \\
quasi-PSO & Power connection point \\
SA & Particle swarm optimization \\
WLAN & Wretwork \\
\hline
\end{tabular}

efficient method for installing telecommunication cabling is presented but with a focus on the relationship of the skill of the cabling work and the installation quality. With respect to human exposure, concerns about the potential health impact of electromagnetic field (EMF) radiation on the human body have arisen [23] and exposure values have been characterized, e.g., in office environments $[24,25]$. In [26], it was shown that in indoor environments, exposure values are relevant. In [27], a metric is proposed to assess the environmental impact (e.g., exposure) of outdoor networks, but coverage is not accounted for and no (automatic) network planning is performed. In [6], an algorithm was presented to limit or minimize exposure in indoor environments, but it only accounted for coverage and the electric-field strength throughout the building. When the network planner imposes multiple requirements (high coverage, low installation cost, and low exposure), more complex optimization algorithms are required. In [28], the network planning problem is solved in radio-frequency identification (RFID) systems by using an altered version of a particle swarm optimization (PSO) algorithm. Genetic algorithms (GAs) have been used in $[9,29]$ for planning wireless communication networks. In [4], coverage and exposure are jointly optimized for indoor networks. In [30], a green optimization metric is used, but it is aimed at outdoor cellular base stations. In [31], energy-efficient wireless access networks are designed. However, none of these takes into account the network installation cost, the provided coverage, and an advanced exposure minimization at a same time for indoor wireless networks.

\subsection{Comparison of algorithm features with other algorithms}

In this section, the specific features of the proposed optimization algorithm are set out against those of previous algorithms. An overview is provided in Table 2. In [4], a GA optimization is performed for designing a homogeneous indoor wireless network with a minimal coverage of $95 \%$ and a minimal safety index, corresponding to a minimal median power density (or electric-field strength). The results show that the generated exposure level can be reduced by optimally placing more transmitters and operating at low power levels. In [6], two heuristic algorithms are proposed for the design of wireless networks with at least $95 \%$ coverage. The first one limits the maximal electric-field in the building at a user-defined level (e.g., in accordance with national regulations) and designs a network with a minimal cost, expressed in number of APs. The second heuristic algorithm minimizes an electricfield-based metric, while providing full coverage (95\%). The results confirm the findings of [4], i.e., that a lower exposure can be obtained by using more APs, but with a lower transmit power. In [32], a PSO algorithm and an ant 
Table 2 Overview of features of related wireless network optimization algorithms

\begin{tabular}{|c|c|c|c|c|c|}
\hline Algorithm type & Output & Optimization criterion & Environment & Simulation time & Ref. \\
\hline $\mathrm{HIGO}$ & AP locations & Maximal coverage, minimal median exposure & $90 \times 17 \mathrm{~m}$ & Dependent on & {$[10]$} \\
\hline (GA with PSO) & and AP EIRP & level (E), minimal cost (\#APs) & office building & PL model & \\
\hline \multirow[t]{5}{*}{ Heuristic } & AP locations & Full coverage (95\%), limited maximal & $90 \times 17 \mathrm{~m}$ & Not & {$[6]$} \\
\hline & and AP EIRP & exposure (E) with minimal cost (\#APs) & office building & specified & \\
\hline & & OR & & & \\
\hline & & Full coverage (95\%) with minimal & & & \\
\hline & & median exposure (E) & & & \\
\hline \multirow[t]{2}{*}{$\overline{G A}$} & AP locations & Full coverage (95\%), minimal median & $40 \times 25 \mathrm{~m}$ office & $20 \mathrm{~min}$ & {$[4]$} \\
\hline & & exposure level (E) & building & & \\
\hline $\mathrm{ACO}, \mathrm{PSO}$ & AP locations & Maximal coverage & $323 \mathrm{~m}^{2}$ university & ACO (814s), PSO & {$[32]$} \\
\hline GA & & of $1 \mathrm{AP}$ & building & $(184 s)$, GA (189s) & \\
\hline \multirow[t]{2}{*}{ GA, SA, DIRECT } & AP locations & Maximal coverage for fixed & $80 \times 22 \mathrm{~m}$ office & Not & {$[33]$} \\
\hline & & number of 1,2 , or 6 APs & building & specified & \\
\hline PSO & AP locations & Maximal coverage, minimal cost (\#APs) & $64 \times 60 \mathrm{~m}$ building & Not specified & [19] \\
\hline Multi-objective Tabu- & AP locations & Maximal coverage, minimal interference, & $12,600 \mathrm{~m}^{2}$ & $3500 \mathrm{~min}$ & {$[7]$} \\
\hline based metaheuristic & & maximal user throughput & building & & \\
\hline PSO & AP locations & Maximal coverage, minimal cost (\#APs) & $40 \times 30 \mathrm{~m}$ building & Not specified & {$[34]$} \\
\hline Mathematical & AP locations & Maximal coverage and throughput, & $84 \times 18 \mathrm{~m}$ office & At most a & [35] \\
\hline optimization & and channel & minimal interference & building & few hours & \\
\hline \multirow[t]{2}{*}{ Heuristic } & AP radio & Maximal coverage, minimal interference, & $100 \times 100 \mathrm{~m}$ & Not & [36] \\
\hline & locations & minimal cost (\#radios and AP boxes) & office building & specified & \\
\hline GA (with BFS) & AP locations & Maximal coverage, minimal cost (\#APs) & $55 \times 40 \mathrm{~m}$ office building & Less than $10 \mathrm{~s}$ & {$[37]$} \\
\hline \multirow[t]{3}{*}{ HIGO updated } & AP locations, & Maximal coverage, minimal exposure & $90 \times 17 \mathrm{~m}$ & $222.3 \mathrm{~s}$ & This \\
\hline & AP EIRP, and cabling & (average SAR per person), minimal & office & & paper \\
\hline & installation solution & cost (full installation cost) & building & & \\
\hline
\end{tabular}

colony optimization (ACO) algorithm are compared with a GA algorithm for finding the optimal location of 1 AP, where the goal is to only optimize coverage. The paper shows that the PSO and GA algorithm have a comparable solution quality and convergence time, while ACO has a significant higher execution time and delivers a slightly worse solution. The work proposed in [33] aims to maximize the coverage with a given and fixed number of APs $(1,2,3$, or 6) for different optimization algorithms: GA, SA, and DIRECT. DIRECT is based on a division of the design space into hyper-rectangles or hypercubes for multidimensional problems. The paper shows that the algorithms allow improvement of a non-optimized deployment. DIRECT performs well for optimizations with at most 2 APs and GA performs slightly better than SA. In [19, 34], PSO optimizations were performed, able to reduce the number of APs for a given deployment [19] or to design a network with a minimal number of APs [34]. In [7], a Tabu-based metaheuristic optimization algorithm is proposed that is focused on QoS, accounting for coverage, interference, and throughput per user. It is shown that a good coverage and high throughput leads to an increased interference. The algorithm does not look at cost or exposure and has a long simulation time. A mathematical optimization approach is applied in [35] for a maximal coverage and throughput on the one hand and a minimal channel overlap (interference) on the other hand. A heuristic is developed in [36] for network design with a maximal coverage with low interference and a minimal cost, accounting for the AP box and the number of contained radios. In [37], a GA with breadth-first search (BFS) is applied to obtain a solution with maximal coverage and minimal number of APs, focusing on a low execution time.

This section shows that previously developed solutions either do not optimize exposure or either the optimization is done for a low median or average field strength in the entire building, whereas our solution progresses the work in [10] and is able to minimize the average wholebody exposure of the actual persons that are present in the different rooms of the building (user-centric approach). 


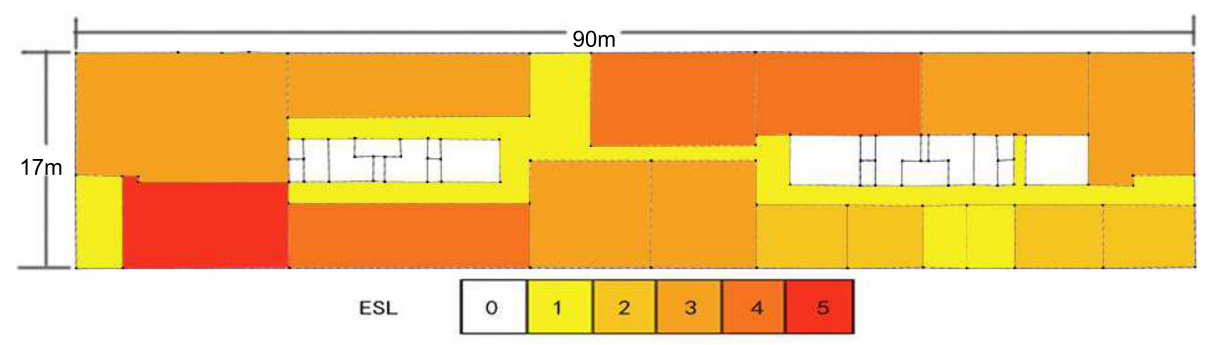

Fig. 1 Map of the considered office environment $(90 \times 17 \mathrm{~m})$ with indication of the ESL distribution (colors indicate exposure sensitivity level ESL; the middle rooms (white) have $E S L=0$ )

It will be shown in Section 6.1 that applying an exposure sensitivity level (ESL) distribution indeed significantly influences the network planning and the resulting exposure in the considered rooms. Further, when other solutions account for the cost, they only aim to minimize the number of installed APs (e.g., previous work in [10]), while it was shown in [11] that this cost is only a fraction of the total cost. The solution presented in this paper therefore takes the entire installation cost into account. Moreover, all calculations are performed within a reasonable time.

\section{Configuration}

\subsection{Simulation environment}

Figure 1 shows a map of the considered environment, the third floor of an office building $(90 \times 17 \mathrm{~m})$ in Ghent. Coverage and electric-field strength will be evaluated at 425 uniformly distributed receiver locations. These locations are created by overlaying a rectangular grid with a user-defined resolution in the considered office environment. In this paper, the grid size is chosen at $2 \mathrm{~m}$. The locations at which the the IEEE 802.11n APs at $2.4 \mathrm{GHz}$ are installed are chosen from a set of 411 possible uniformly distributed locations on the building floor. These 411 locations are a subset of the 425 locations, since at some of the calculated 425 locations, no AP can be installed (e.g., the room space is too small to install cable and device).

\subsection{Coverage model and link budget}

The path loss PL $(d)[\mathrm{dB}]$ is modeled according to the heuristic model defined in [38, 39]:

$$
\mathrm{PL}(d)=\mathrm{PL}\left(d_{0}\right)+10 \cdot n \cdot \log _{10}\left(\frac{d}{d_{0}}\right)+\sum_{i} L_{W i}+\sum_{j} L_{B j},
$$

with PL $\left(d_{0}\right)[\mathrm{dB}]$ the path loss at a reference distance $d_{0}[\mathrm{~m}]$ (set at $1 \mathrm{~m}$ here) according to the distance loss model, $d[\mathrm{~m}]$ is the distance along the path between access point and receiver, $n[-]$ is the path loss exponent, $\sum_{i} L_{W i}$ is the cumulated wall loss along the path, and $\sum_{j} L_{B j}$ is the interaction loss accounting for propagation direction changes of the path. The model takes into account the effect of the physical environment on the electromagnetic propagation and bases its calculations on the determination of the dominant path between transmitter and receiver [39]. The electricfield strength is calculated based upon this model, as presented in [6].

The equivalent isotropically radiated power (EIRP) of the access points (802.11n, Section 3.1) will be varied between 0 and $20 \mathrm{dBm}$ by the algorithm, the receiver antenna gain is $0 \mathrm{dBi}$, and the shadowing margin and fading margin are set at $7 \mathrm{~dB}(95 \%)$ and $5 \mathrm{~dB}$ (99\%), respectively. All networks will be planned for a capacity of $54 \mathrm{Mbps}$. This corresponds with a required received power of $-68 \mathrm{dBm}$. We select this bit rate and sensitivity to enable us to demonstrate challenging scenarios. Table 3 summarizes the configuration settings.

\subsection{Exposure sensitivity levels}

An advanced exposure minimization technique will be applied, where different rooms will have different sensitivity levels. The ESL of a room is expressed as a number that reflects to which extent high exposure values are considered as adverse. Higher ESL numbers in rooms mean higher sensitivities, i.e., exposure should be lowered (see Fig. 1). This approach will allow designing a network

Table 3 Simulation configuration settings of AP (802.11n), receiver, and channel

\begin{tabular}{cc}
\hline Items & Values \\
\hline Receiver sensitivity & $-68 \mathrm{dBm}$ \\
Receiver antenna gain & $0 \mathrm{dBi}$ \\
Transmitter gain & $2 \mathrm{dBi}$ \\
Frequency & $2.4 \mathrm{GHz}$ \\
AP EIRP range & $0-20 \mathrm{dBm}$ \\
Shadowing margin (95\%) & $7 \mathrm{~dB}$ \\
Fading margin (99\%) & $5 \mathrm{~dB}$ \\
\hline
\end{tabular}


Table 4 Unit prices of components contributing to total installation cost

\begin{tabular}{cc}
\hline Items & Unit price \\
\hline Cable gutter & $13.065 € / \mathrm{m}$ \\
Ethernet cable & $1.5 € / \mathrm{m}$ \\
Power cable & $4.55 € / \mathrm{m}$ \\
AP & $86 €$ \\
Drilling hole layered drywall & $5 €$ \\
Drilling hole concrete wall & $20 €$ \\
& \\
Labor & $67.5 € / \mathrm{h}$ \\
Installing APs & $2 / \mathrm{h}$ \\
Installing cables & $15 \mathrm{~m} / \mathrm{h}$ \\
Drilling holes & $5 / \mathrm{h}$ \\
\hline
\end{tabular}

where in rooms with a high number of people, exposure levels are reduced without impairing coverage. In previous research [6], no differentiation was made between the rooms of a building. Six ESLs are defined in Fig. 1, ranging from 0 to 5 . For some rooms, no coverage is required (e.g., sheds, elevator shafts, kitchens,...), since these are rarely visited. These rooms are represented with a white color $(E S L=0)$ in Fig. 1 . The five other ESL values $(E S L=1$ to $\mathrm{ESL}=5$ ) are indicated in Fig. 1 with progressively darker colors. The one room with the ESL equal to 5 (bottom left in Fig. 1) is a pc room where usually a lot of people are present. The exact ESL of a room is ideally determined by the total absorbed exposure dose of all people in the different rooms. Besides on the field strength level, this total exposure dose also depends on the average total number of people in each room and the morphology of these people (adults vs. children). For example, the ESL of the corridor is set at 1 , since people mostly walk through this area instead of staying there for a long time. In the following section, it is shown how room ESLs are determined mathematically.

\subsubsection{Determination of ESLs}

Given the average number of people in each room and their whole-body SAR, each room's ESL can be derived as follows. The whole-body SAR of one person $p$ is calculated as $\operatorname{SAR}_{\mathrm{wb}}^{p}$ :

$$
\mathrm{SAR}_{\mathrm{wb}}^{p}=S \cdot \mathrm{SAR}_{\mathrm{wb}}^{\mathrm{REF}, p}=\frac{E^{2}}{377} \cdot \mathrm{SAR}_{\mathrm{wb}}^{\mathrm{REF}, p},
$$

with $S$ the power density and $E$ the electric-field strength at the person's location and $S A R_{w b}^{R E F}, p$ the reference wholebody SAR of the person $p$, which is different for adults and children. Since the total SAR of all people in the building is the sum of all $\mathrm{SAR}_{\mathrm{wb}}^{p}$ values, Eq. 2 shows that the sum of all reference SARs $\mathrm{SAR}_{\mathrm{wb}}^{\mathrm{REF}, p}$ of the people present in a room is a measure for the contribution of that room's $E^{2}$ to the total SAR of all people in the building. This sum of the $\mathrm{SAR}_{\mathrm{wb}}^{\mathrm{REF}, p}$ values of persons $p$ in a certain room is hereafter called the room's total reference SAR and is denoted as $\mathrm{SAR}_{\mathrm{wb}}^{\mathrm{REF}, \mathrm{room} \text { : }}$

$$
\mathrm{SAR}_{\mathrm{wb}}^{\mathrm{REF}, \text { room }}=\sum_{\substack{p=\text { person } \\ \text { in room }}} \mathrm{SAR}_{\mathrm{wb}}^{\mathrm{REF}, p}
$$

Since ESLs are expressed in terms of $E$ (and SAR is proportional to power density or to $E^{2}$ ), the square root of the room's total reference SAR is a measure for the room's ESL.

$$
\mathrm{ESL}^{\text {room }}=\sqrt{\mathrm{SAR}_{\mathrm{wb}}^{\mathrm{REF}, \mathrm{room}}}
$$

It can be considered as a good practice to linearly rescale all obtained ESLs to have to lowest non-zero ESL equal to 1 . This is done by dividing each $\mathrm{ESL}^{\text {room }}$ by the lowest non-zero ESL ${ }^{\text {room }}$ value.

\subsection{Installation cost}

In this paper, for the first time, an indoor planning optimization algorithm is used which accounts for the full installation cost of an indoor environment. Access points only function if they are connected to both a power connection point (PCP) and an ethernet connection point (ECP). Therefore, the total cost of installing the connection cables should also be accounted for. The cost minimization algorithm is based on graph theory and works as described in [11]. The algorithm optimizes the location and the amount of power and ethernet cables that are needed to connect each AP in the considered indoor

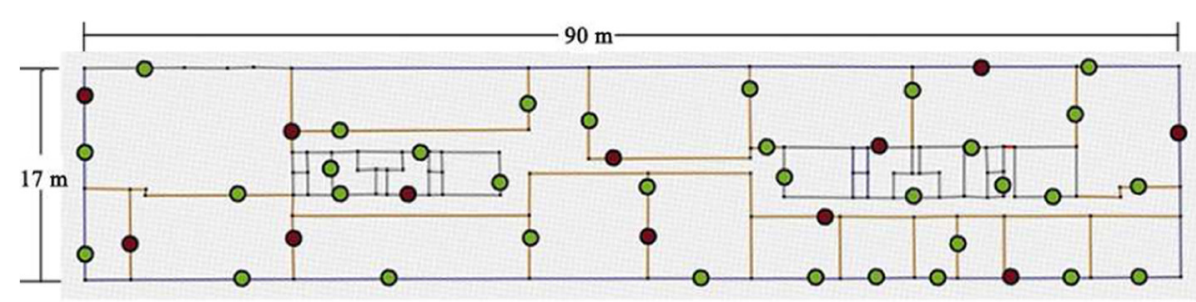

Fig. 2 Assumed distribution of power connection points (green) and ethernet connection points (red) in the considered office environment 
environment to both a PCP and an ECP with the lowest possible cost, based on the algorithm's input data: the $A P, P C P$, and ECP positions, the cost of cable (ethernet and power) and cable gutter (containing the cables) per meter, drilling holes through walls (material-dependent), and working hours. The number of working hours is determined by the number of holes to be drilled through walls, the number of meters of cables and cable gutters to be installed (dependent on the material of the wall they are attached to), and the number of APs to be installed. It is clear that the physical layout of the ground plan will greatly influence the output of the algorithm. Table 4 lists the assumed prices of the different cost types. Depending on the amount and location of PCPs and ECPs, the optimal positions of the APs and the total cost will vary. Figure 2 shows a possible set of PCPs and ECPs. The 33 green dots represent the PCPs, and the 12 red dots represent the ECPs.

\section{Optimization system}

\subsection{High-level overview}

Figure 3 shows a high-level tool chain of the system. A path loss model from the library is applied to the inputted floor plan and chosen receiver. The network characteristic calculation algorithm can then, based on these inputs, calculate the coverage and exposure characteristics of a network. Further, the cost calculation algorithm is able to calculate the total installation cost of a network, given the floor plan and the cost input parameters (e.g., the cost per meter cable,...). The optimization algorithm uses the joint outputs of the network characteristic calculation algorithm (coverage, exposure) and the cost calculation algorithm (cost) to find an optimal output solution (AP locations, AP transmit power, cabling). The following section will focus on the optimization algorithm itself.

\subsection{Optimization algorithm}

The optimization algorithm is based on the hybrid indoor genetic optimization (HIGO) algorithm described in [10]. It is a combination of a GA and a quasi-particle swarm optimization (quasi-PSO) algorithm and determines the locations and the EIRP of the APs in the different scenarios. Figure 4 shows a flow graph of the algorithm.
In step 1, a starting population of 1000 random solutions is generated for the considered environment. In step 2 , the scenario's fitness function is used to calculate the fitness values for all starting solutions. The 40 solutions with the highest fitness values are stored in a first list; the 60 next best solutions in the are stored in a second list. In step 3, 100 crossover solutions are created and evaluated. Offspring solutions are generated by randomly recombining two parent solutions: one from the first list and one from the second list. Due to the smaller size of the first list, solutions in this list have a higher probability of being selected for recombination than solutions in the second list. In step 4, parts of solutions are changed by the mutation operation by introducing new genetic material into the population. This basically corresponds with changing the location and/or EIRP of APs of the solution. Within step 4, 50 mutated solutions are created and evaluated. Compared to [10], the algorithm is improved by a deepened hybrid of the quasi-PSO algorithm: unlike only allowing quasi-PSO for solutions with one AP, all solutions can possibly undergo a quasi-PSO operation, with a chance of $25 \%$ (hybrid part). In the mutation phase, a list with the best previous solutions is created for different numbers of APs in a solution. If the fitness values of the mutated solution are higher than that of the previous best solution with the same number of APs, the previous solution is replaced by the newly generated solution. Otherwise, a new solution is created according to the following equation (quasi-PSO):

$$
X_{i+1}=X_{i}+a\left(X_{\text {Best }}-X_{i}\right)+b X_{R},
$$

with $\mathrm{X}=$ location/EIRP, the subscripts " $i$ " and " $i+1$ " refer to the previous and the new location/EIRP, respectively. The subscript " $r$ " refers to a random location/EIRP. This random location/EIRP is introduced to avoid getting stuck in local optima. Subscript "best" refers to the location/EIRP of the nearest AP in the best solution. Parameters $a$ and $b$ are the scaling factors associated with the differences $\left(X_{\text {Best }}-X_{i}\right)$ and $X_{R}$, respectively. Whereas $\left(X_{\text {Best }}-X_{i}\right)$ represents the tendency towards the region of the best location/EIRP, $X_{R}$ introduces the capability to discover new solutions. Parameters $a$ and $b$ can be considered as acceleration constants. The higher the $a$ and $b$, the

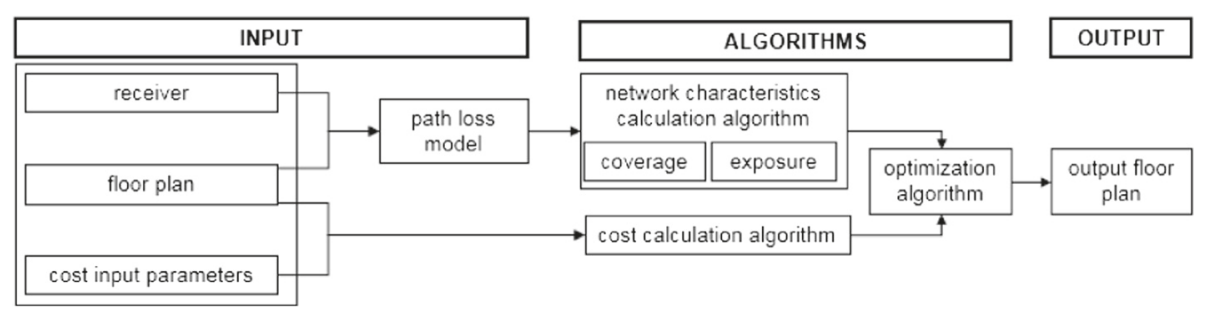

Fig. 3 High-level overview of the optimization system with indication of the different inputs, the involved modules, and the output 


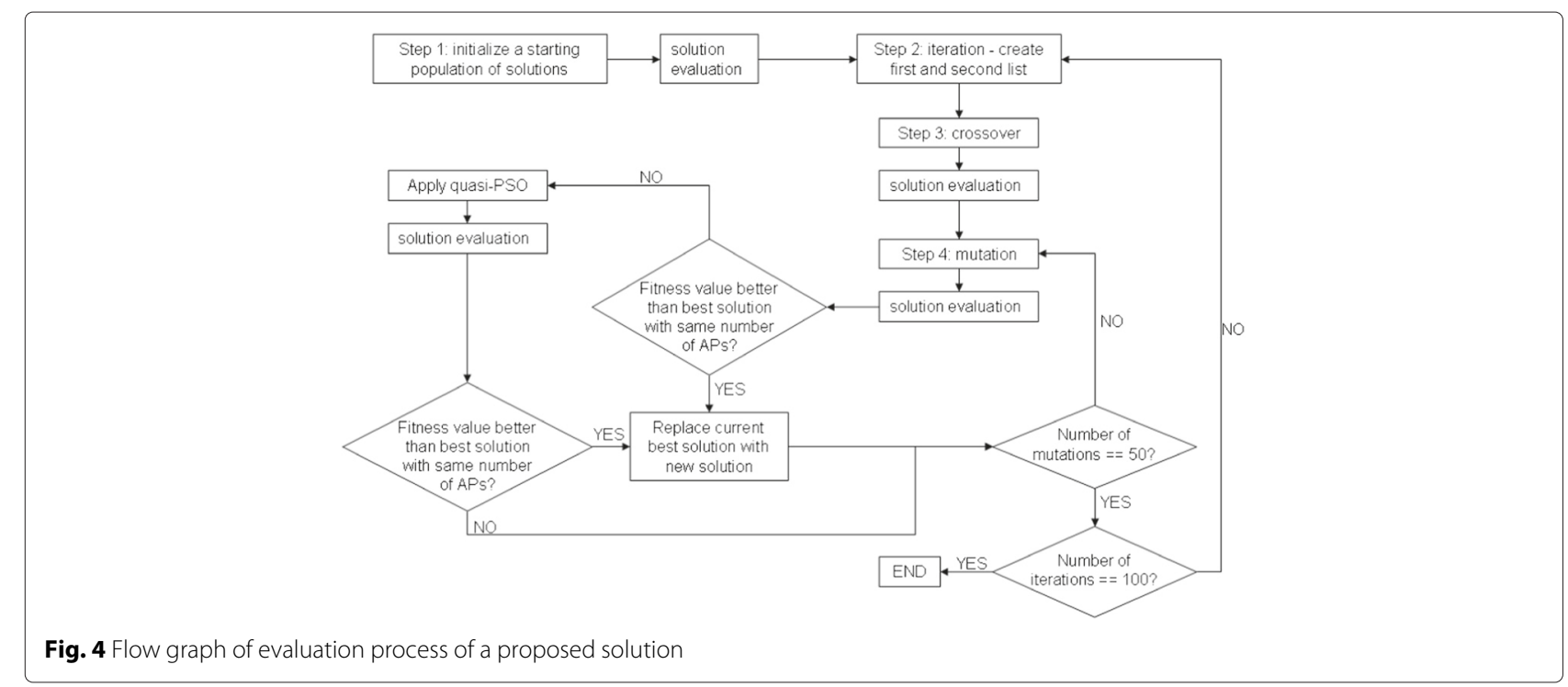

higher the acceleration towards the current best position and the random position, respectively. In this paper, they are both equal to 0.4. After step 4, a new iteration from step 2 is started by resorting the first and second list based on their fitness value. In this paper and for the considered environment, the algorithm is stopped after 100 executed iterations of steps 2, 3, and 4. In the next section, it is explained how a proposed solution is evaluated ("solution evaluation" block in Fig. 4).

\subsection{Solution evaluation}

Each solution that is proposed by the optimization algorithm, whether being randomly generated or by a crossover or mutation operation, consists of a set APs, each with a specific location and EIRP. As shown in Fig. 5, together with the fitness function that is considered for the scenario, this set of APs serves as an input to the solution evaluation module of the algorithm. Based on the phyiscal properties (walls, dimensions,...) of the floor plan, the location and EIRP of the APs, the location of the DCPs and ECPs, the type of receiver, the path loss model, and the cost input parameters, the network calculator predicts the output characteristics of the wireless network. This comprises the coverage and field strength value in each receiver point and the total installation cost of the wireless network. Using the proposed fitness function, this output allows an evaluation of the fitness function value. In the next section, the building blocks for the fitness functions will be discussed: coverage fitness, installation cost fitness, and exposure fitness based on ESLs.

\subsection{Coverage fitness}

The first fitness function $f_{1}$ evaluates the coverage for a certain literature capacity of a certain solution and will often be the most important requirement.

$$
f_{1}=100 \frac{f_{\text {cov }}}{f_{\text {tot }}}
$$

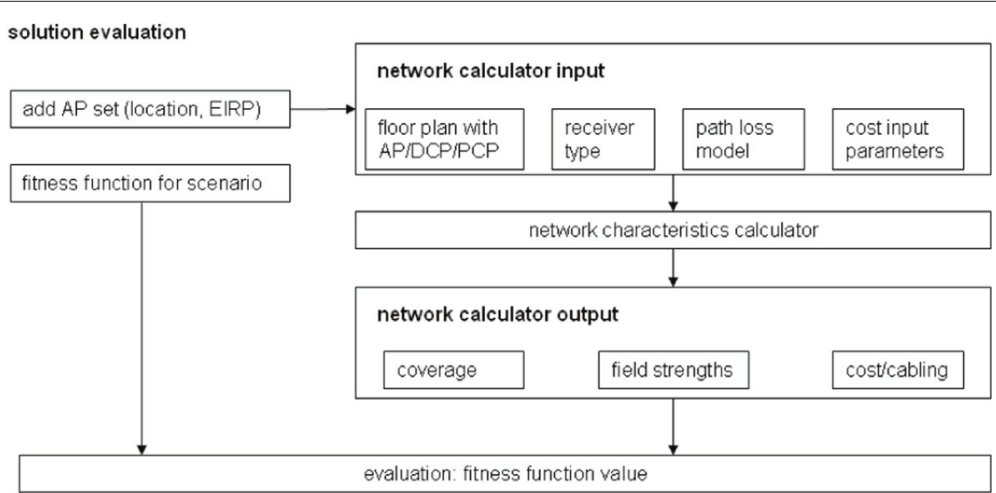

Fig. 5 Flow graph of evaluation process of a proposed solution 


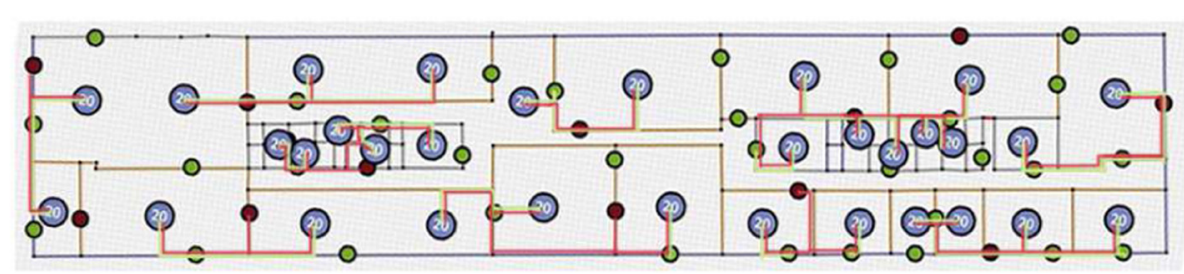

Fig. 6 The normal connection point distribution (green = power, red = ethernet) and the considered solution with cost cost $t_{m a x}$ (purple dots represent APs, EIRP is shown inside dot)

where $f_{\text {cov }}$ is the number of receiver points covered by the wireless network and $f_{\text {tot }}$ is the total number of receiver points requiring coverage. $f_{1}$ will have a value between 0 and 100.

\subsection{Installation cost fitness}

As indicated in Section 3.4, different network deployments may correspond with largely different installation costs. $f_{2}$ represents the installation cost fitness:

$$
f_{2}=100 \frac{\text { cost }_{\text {total }}}{\text { cost }_{\max }} \text {. }
$$

cost $_{\text {total }}$ represents the total installation cost of the considered network design. However, to evaluate the fitness, it should be set out against a reference maximal cost cost $t_{\max }$. As cost $t_{\max }$, the installation cost of the network in Fig. 6 is assumed, in which 32 APs are installed, one or two in each of the larger rooms, zero in the very small rooms. The light green lines represent the power cables, and the red lines represent the ethernet cables. For this configuration, cost $_{\text {max }}$ equals $€ 10312$. $f_{2}$ will, for all deployments here considered, have a value between 0 and 100 .

\subsection{Exposure fitness}

Two exposure fitness functions are defined. The calculation of the first exposure fitness function, $f_{3}$, is based on the electric-field strength observed at the receiver locations, and on the ESLs of the rooms:

$$
f_{3}=100 \frac{E_{50}^{\mathrm{ESL}}}{E_{50 \max }^{\mathrm{ESL}}},
$$

with $E_{50}^{\mathrm{ESL}}$ the median of the electric-field strengths (in $\mathrm{V} / \mathrm{m})$ at the different receiver locations. The ESL of the room of the receiver location is accounted for by giving locations in high ESL rooms more weight: an electric-field strength $E$ at a receiver location inside a room with $\mathrm{ESL}=i$ $(i=0 . .5)$ is added $i$ times to the cumulative distribution function (CDF) of the field strengths. For example, an electric-field strength $E=0.1 \mathrm{~V} / \mathrm{m}$ in the corridor in Fig. 1 $(\mathrm{ESL}=1)$ contributes to the global cdf with one $0.1 \mathrm{~V} / \mathrm{m}$ value, while an electric-field strength $E=0.4 \mathrm{~V} / \mathrm{m}$ in the top left room in Fig. $1(\mathrm{ESL}=3)$ contributes to the global CDF with three $0.4 \mathrm{~V} / \mathrm{m}$ values. $E_{50 \max }^{\mathrm{ESL}}$ is defined as $E_{50}^{\mathrm{ESL}}$ for a configuration with maximal electric-field strengths (all 411 APs are active with an EIRP value of $20 \mathrm{dBm}$ ). Whereas the first exposure fitness function assesses the median field values, the second one, $f_{4}$, also represents the spatial homogeneity (i.e., absence of large spatial variations) of the field strengths, by minimizing the maximal (95th percentiles) field values instead of the median field values in $f_{3}$ :

$$
f_{4}=100 \frac{E_{95}^{\mathrm{ESL}}}{E_{95 \max }^{\mathrm{ESL}}}
$$

where $E_{95}^{\mathrm{ESL}}$ and $E_{95 \max }^{\mathrm{ESL}}$ are defined as $E_{50}^{\mathrm{ESL}}$ and $E_{50 \mathrm{max}}^{\mathrm{ESL}}$, respectively, but for the $95 \%$ percentile instead of for the $50 \%$ percentile. The $E_{50 \max }^{\mathrm{ESL}}$ (in Eq. 8) and $E_{95 \max }^{\mathrm{ESL}}$ (in Eq. 9) values are 10.95 and $59 \mathrm{~V} / \mathrm{m}$, respectively, for this environment. For all deployments here considered, $f_{3}$ and $f_{4}$ will have a value between 0 and 100 . By weighing the field strengths with the room's ESL, the exposure minimization algorithm advances current methods by enabling minimization of specific rooms that are sensitive to a higher exposure.

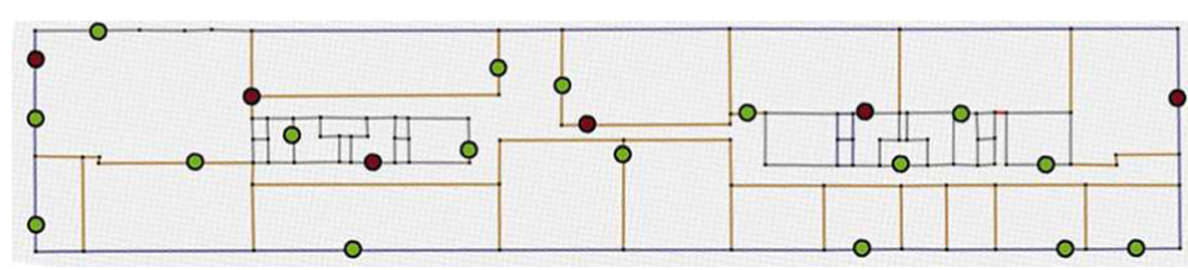

Fig. 7 Ground plan with a reduced set of available connection points 


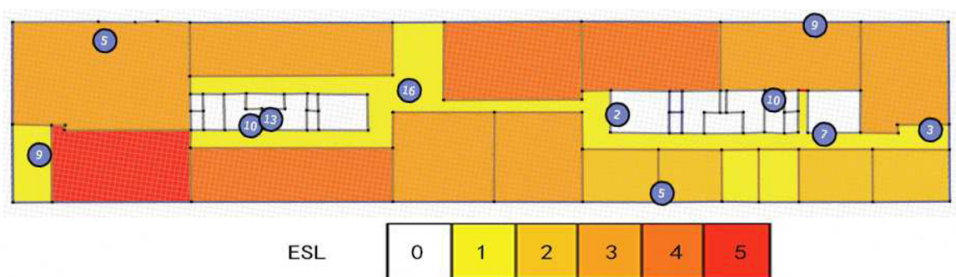

(a) First ESL distribution

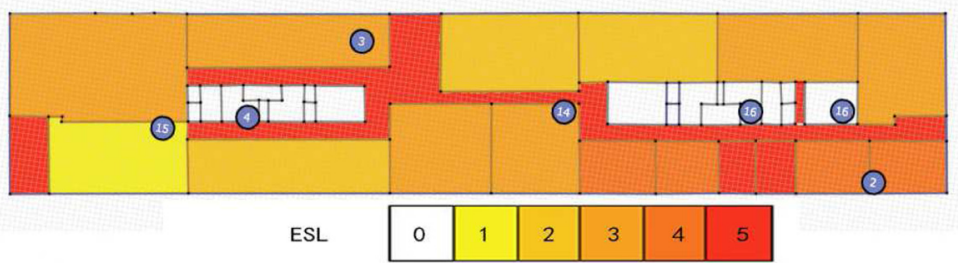

(b) Second ESL distribution

Fig. 8 Network layout for scenario I with indication of ESL distribution (purple dot = AP with EIRP indicated inside dot, colors inside rooms (see legend) indicate ESL). a First ESL distribution. b Second ESL distribution

\subsection{Combined fitness function}

Combination of the four presented fitness functions in a global fitness function $f_{5}$ allows optimizing networks that are subject to multiple requirements:

$$
f_{5}=w_{1} f_{1}-w_{2} f_{2}-w_{3} f_{3}-w_{4} f_{4} .
$$

Depending on the specific aim of the network design, the value of the weights $w_{i}(i=1 . .4)$ can be determined. The optimal solution is the one with the highest fitness function $\left(f_{5}\right)$ value, as it corresponds to the highest coverage percentage, the lowest total installation cost, and the lowest exposure values.

\section{Scenarios}

In this section, three scenarios are defined to investigate the impact of coverage (required bit rate of $54 \mathrm{Mbps}$ ), installation cost, and human exposure requirements on the network planning of the office environment in Fig. 1. The specific network requirements will determine the fitness functions that will be used in the optimization algorithm.

\subsection{Scenario I: maximal coverage with minimal human exposure}

Scenario I intends to obtain a coverage rate of $100 \%$ for a capacity of $54 \mathrm{Mbps}$ with a minimal median exposure and a high spatial homogeneity. The weight factors, $w_{3}$ and $w_{4}$ in Eq. 10, need to be a positive number. In this way, the algorithm will obtain a solution with a low exposure level, in order to achieve $100 \%$ coverage at $54 \mathrm{Mbps}$. This yields the following fitness function $f_{5}$ (see Eq. 10):

$$
f_{5}=1 \times f_{1}-0.1 \times f_{3}-0.1 \times f_{4},
$$

The values of $w_{3}$ and $w_{4}$ are chosen at 0.1 , making the total exposure weight equal to $0.2 . w_{1}$ is set at 1 to make the coverage fitness dominant over the exposure fitness and obtain a solution with $100 \%$ coverage for a capacity of $54 \mathrm{Mbps}$. This scenario will be tested for two different ESL distributions. The first ESL distribution is the one displayed in Fig. 1. In order to assess the influence of the ESL distributions, a second ESL distribution is defined, which is the reversed version of the first one: rooms with $\mathrm{ESL}=1,2,3,4,5$, according to the first ESL distribution, have $\mathrm{ESL}=5,4,3,2$, and 1, respectively, according to the second ESL distribution. This will allow assessing the influence of the ESL distribution on the field values in rooms with different ESLs and on the resulting network planning layout.

Table 5 Median field values $E_{50}$ per room for the first ESL distribution (Fig. 8) $(R i, i=1 . .18$ represents room number $i)$

\begin{tabular}{ccc}
\hline ESL & $E_{50}$ for each room $[\mathrm{mV} / \mathrm{m}]$ & Average $E_{50}^{\mathrm{ESL}}[\mathrm{mV} / \mathrm{m}]$ \\
\hline 5 & $44(\mathrm{R} 1)$ & 44 \\
4 & $57(\mathrm{R} 2)-75(\mathrm{R} 3)-32(\mathrm{R} 4)$ & 55 \\
3 & $105(\mathrm{R} 5)-47(\mathrm{R} 6)-51(\mathrm{R} 7)$ & 72 \\
& $74(\mathrm{R} 8)-48(\mathrm{R} 9)-105(\mathrm{R} 10)$ & \\
2 & $53(\mathrm{R} 11)-74(\mathrm{R} 12)-64(\mathrm{R} 13)-38(\mathrm{R} 14)$ & 58 \\
1 & $235(\mathrm{R} 15)-87(\mathrm{R} 16)-32(\mathrm{R} 17)-42(\mathrm{R} 18)$ & 99 \\
\hline
\end{tabular}


Table 6 Median field values $E_{50}$ per room for the second ESL distribution (Fig. 8) $(R i, i=1 . .18$ represents room number $i)$

\begin{tabular}{lcc}
\hline ESL & $E_{50}$ for each room $[\mathrm{mV} / \mathrm{m}]$ & Average $E_{50}^{\mathrm{ESL}}[\mathrm{mV} / \mathrm{m}]$ \\
\hline 1 & $156(\mathrm{R} 1)$ & 156 \\
2 & $50(\mathrm{R} 2)-62(\mathrm{R} 3)-42(\mathrm{R} 4)$ & 52 \\
3 & $52(\mathrm{R} 5)-148(\mathrm{R} 6)-78(\mathrm{R} 7)$ & 105 \\
& $53(\mathrm{R} 8)-42(\mathrm{R} 9)-48(\mathrm{R} 10)$ & \\
4 & $72(\mathrm{R} 11)-36(\mathrm{R} 12)-58(\mathrm{R} 13)-53(\mathrm{R} 14)$ & 55 \\
5 & $54(\mathrm{R} 15)-49(\mathrm{R} 16)-47(\mathrm{R} 17)-49(\mathrm{R} 18)$ & 50 \\
\hline
\end{tabular}

\subsection{Scenario II: maximal coverage with minimal installation cost}

Scenario II aims to obtain a solution with a coverage rate of $100 \%$ for a capacity of $54 \mathrm{Mbps}$ and a minimal installation cost. $w_{2}$ for scenario II is chosen based on the similar principle to that of scenario I. This yields the following fitness function $f_{5}$ :

$$
f_{5}=1 \times f_{1}-0.2 \times f_{2} .
$$

The value of $w_{2}$ is chosen at 0.2 here, making the coverage fitness $\left(w_{1}=1\right)$ dominant over the installation cost fitness and again obtain a solution with $100 \%$ coverage for a capacity of $54 \mathrm{Mbps}$. This scenario will be tested for two different configurations: one with the set of connection points (CPs) as in Figs. 2 and 6, and one with a reduced set of possible connection points, as displayed in Fig. 7. This will allow assessing the influence of the size of the connection point set on the total installation cost and on the resulting network planning layout.

\subsection{Scenario III: maximal coverage with minimal human exposure and minimal installation cost}

Scenario III intends to obtain a coverage rate of $100 \%$ for a capacity of $54 \mathrm{Mbps}$ with a minimal installation cost, minimal median exposure values, and a high spatial homogeneity of the field values. As for weight factors of $f_{5}$, the ratio of weight factors $\left(w_{1}, w_{2}, w_{3}\right.$, and $\left.w_{4}\right)$ can be adapted based on the different requirements, which generate solutions with the different characteristics. The influence of weight factors are similar with those of in [10]. In scenario III, fixed weight values are considered. This yields the following fitness function $f_{5}$ :

$$
f_{5}=1 \times f_{1}-0.2 \times f_{2}-0.1 \times f_{3}-0.1 \times f_{4} .
$$

Table 7 Performance of old algorithm and new improved

\begin{tabular}{|c|c|c|c|c|}
\hline \multirow{2}{*}{$\frac{\text { Algorithm }}{\text { Old algorithm }}$} & \multicolumn{4}{|c|}{ Coverage $[\%] E_{50}^{\mathrm{ESL}}[\mathrm{mV} / \mathrm{m}] E_{95}^{\mathrm{ESL}}[\mathrm{mV} / \mathrm{m}]$ Simulation time $[\mathrm{s}]$} \\
\hline & 100 & 47.8 & 146.4 & 215.5 \\
\hline New algorithm & 100 & 46.5 & 132.4 & 222.3 \\
\hline
\end{tabular}
algorithm
The value of $w_{2}$ is again chosen at 0.2 here, making the installation cost fitness of equal importance as the total exposure fitness $\left(w_{3}=w_{4}=0.1\right)$. The coverage fitness $\left(w_{1}=1\right)$ is still dominant over the installation cost and exposure fitness, yielding optimal solutions with $100 \%$ coverage for a capacity of $54 \mathrm{Mbps}$. This scenario will be executed for the ESL distribution shown in Fig. 1 and for the two different connection point distributions presented in Section 5.2. It should be noted that for all scenarios, the ratio of the weights $w_{1}$ and $w_{2}, w_{3}$, and $w_{4}$ is large enough to ensure a coverage percentage of (nearly) $100 \%$. A drastic reduction of this ratio would lead to results that are suboptimal for the goal of this optimization (coverage percentage below, e.g., $95 \%$ or worse). In general, a high importance of a low median and $95 \%$ percentile exposure (high values for $w_{3}$ and $w_{4}$, respectively) will lead to wireless deployments with smaller coverage percentages and higher installation cost, which can be countered by increasing $w_{1}$ and $w_{2}$, respectively. Depending on the deemed importance of each specific optimization goal (coverage, cost, median exposure, maximal exposure), the value of the weights can be freely adjusted to favor the achievement of one or more (possibly conflicting) goals.

\section{Results}

This section analyzes the characteristics of the optimized wireless networks, according to the scenarios defined in Section 5. It should be noted that all network layouts that will be presented hereafter correspond to a coverage rate of $100 \%$ for a capacity of $54 \mathrm{Mbps}$. This is due to giving $f_{1}$ a higher weight than the other fitness components $\left(f_{2}, f_{3}\right.$, and $f_{4}$ ) in all three scenarios.

\subsection{Scenario I: maximal coverage with minimal human exposure}

Figure $8 \mathrm{a}$ and $8 \mathrm{~b}$ shows the optimal layout of the network designed in scenario I for the first and second ESL distribution, respectively. The locations of the APs are indicated with purple dots and their EIRP with a value inside the purple dot. The figures show that in both cases, access points are preferably placed in rooms with low ESL values, as could be expected.

In order to quantify the impact of the ESL distribution, median exposure levels per room are calculated. They are presented in Tables 5 and 6, for the first (Fig. 8a) and second (Fig. 8b) ESL distribution, respectively. In order to allow comparison of rooms for the two ESL distributions, room identifiers are indicated between brackets as $R i$, with $i=1 . .18$ the room number among the rooms with $\mathrm{ESL}>0$. Tables 5 and 6 also show the average median field values for all rooms with a certain ESL value. Tables 5 and 6 show that the exposure levels are indeed lower in rooms with higher ESL values: average median values of $99 \mathrm{mV} / \mathrm{m}$ for 


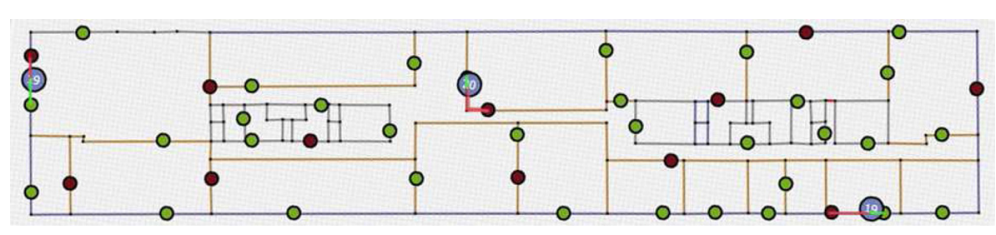

(a) Normal set of connection points

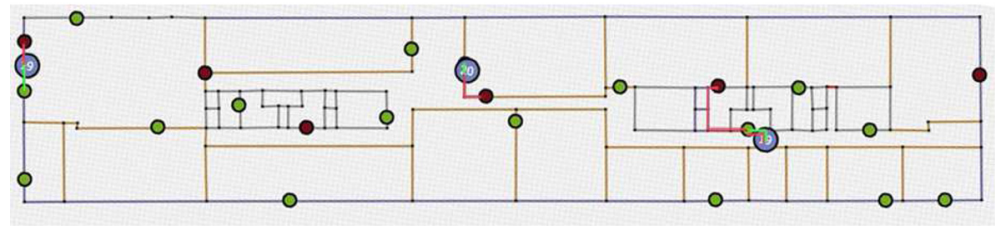

(b) Reduced set of connection points

Fig. 9 Resulting network layout for scenario II with indication of cabling (red dot/line = ethernet CP/cable, green dot/line $=$ power CP/cable, purple $d o t=A P$ with EIRP indicated inside dot). a Normal set of connection points. $\mathbf{b}$ Reduced set of connection points

$\mathrm{ESL}=1$ vs. $44 \mathrm{~V} / \mathrm{m}$ for $\mathrm{ESL}=5$ for the first ESL distribution and $156 \mathrm{mV} / \mathrm{m}$ for $\mathrm{ESL}=1 \mathrm{vs} .50 \mathrm{~V} / \mathrm{m}$ for $\mathrm{ESL}=5$ for the second ESL distribution. Indeed, reversal of the ESL distributions leads to significant changes in median exposure levels: the average median exposure level for room 1 for the second ESL distribution $(\mathrm{ESL}=1)(156 \mathrm{mV} / \mathrm{m})$ is $255 \%$ larger than for the first ESL distribution $(\mathrm{ESL}=5)(44 \mathrm{mV} / \mathrm{m})$. Analogously, for rooms $15-18$, the average median exposure level for the second ESL distribution $(E S L=5)(50 \mathrm{mV} / \mathrm{m})$ is $49 \%$ less than for the first ESL distribution $(E S L=1)(99 \mathrm{mV} / \mathrm{m})$. The results indicate the benefits of introducing the ESL distributions for advanced exposure minimization in indoor wireless networks and accounting for "sensitive rooms" (e.g., where children or a lot of people are present).

\subsubsection{Scenario I: performance improvement of improved algorithm}

As an illustration of the performance improvement of the optimization algorithm compared to [10], the old and the new algorithm have been applied to scenario I. Table 7 shows the average results over 10 algorithm executions.

Table 7 shows that all of the generated solutions achieve $100 \%$ coverage rate. The $E_{50}^{\mathrm{ESL}}$ and $E_{95}^{\mathrm{ESL}}$ of the old algorithm are higher ( +3 and $+11 \%$, respectively) than those of the new algorithm. The simulation time of the new algorithm is slightly higher $(+3 \%)$.

\subsection{Scenario Il: maximal coverage with minimal installation cost}

Figure 9a and 9b shows the optimal layout of the network designed in scenario II for the configuration with a normal set and with a reduced set of connection points, respectively. The locations of the APs are again indicated with purple dots and their EIRP with a value inside the purple dot. Green cables represent power cables and red cables represent ethernet cables. The figures show that all APs are preferably located close to ECPs and PCPs, in order to reduce the amount of cables and cable gutters needed. Both configurations require 3 APs, but less cabling will have to be installed in Fig. 9a, due to the presence of more connection points, leading to a lower total cost. The rightmost AP in Fig. 9b is relocated compared to Fig. 9a, in order to be located closer to an ECP.

Table 8 lists a cost analysis for the two connection point distributions. The individual costs are obtained from confidential interviews with wireless network deployment

Table 8 Installation cost analysis for $54 \mathrm{Mbps}$

\begin{tabular}{cccc}
\hline Item & Amount & Cost $[€]$ & Percentage of total cost [\%] \\
\hline Normal set of connection points (Fig. 2, Fig. 9) & \\
\hline Cable gutter & $15.93 \mathrm{~m}$ & 208.13 & 30.6 \\
AP & 3 & 258 & 38 \\
Ethernet cable & $11.46 \mathrm{~m}$ & 17.2 & 2.5 \\
Power cable & $5.37 \mathrm{~m}$ & 24.44 & 3.6 \\
Holes & 0 & 0 & 0 \\
Labor & $2.56 \mathrm{~h}$ & 172.93 & 25 \\
Total & - & 680.69 & - \\
\hline Reduced set of connection points (Fig. 7, Fig. 9) & \\
\hline Cable gutter & $21.95 \mathrm{~m}$ & 286.8 & 44 \\
AP & 3 & 258 & 29 \\
Ethernet cable & $18.65 \mathrm{~m}$ & 27.97 & 5 \\
Power cable & $6.4 \mathrm{~m}$ & 29.14 & 3 \\
Holes & 3 & 60 & 0.4 \\
Labor & $3.56 \mathrm{~h}$ & 240.53 & 27 \\
Total & - & 902.43 & - \\
\hline
\end{tabular}




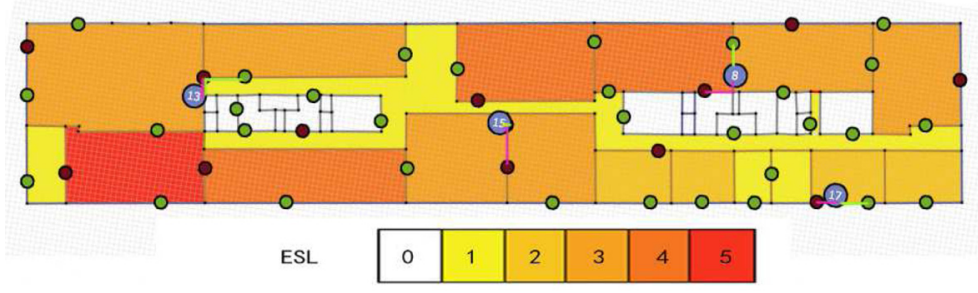

(a) Normal set of connection points

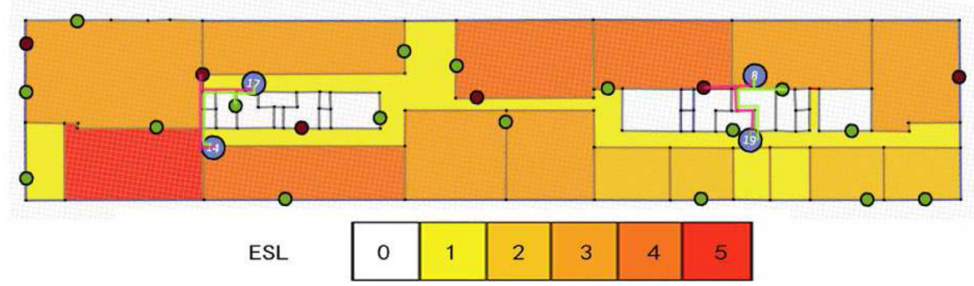

(b) Reduced set of connection points

Fig. 10 Resulting network layout for scenario III with indication of cabling (red dot/line = ethernet CP/cable, green dot/line= power CP/cable, purple $d o t=$ AP with EIRP indicated inside dot, colors inside rooms (see legend) indicate ESL). a Normal set of connection points. b Reduced set of connection points

companies. It shows that the configuration with fewer connection points indeed leads to a higher total cost: $€ 902$ vs. $€ 681$ or an increase of $32 \%$. Table 8 shows that this is due to the higher total cabling cost for connecting the rightmost AP in Fig. $9 \mathrm{~b}$ to an ECP and to the higher labor cost associated with connecting this AP (drilling of three holes and installing more cables and cable gutters). The tables show that the AP cost is always below half of the total price, indicating the importance of performing a full cost analysis and not only accounting for the AP cost when planning wireless networks. Labor costs amount to about one-fourth of the total cost for both connection point configurations. The cost of the cables $(6-8 \%)$ is negligible compared to the cost of the cable gutters (31 and $44 \%$ for the two configurations).

\subsection{Scenario III: maximal coverage with minimal human exposure and minimal installation cost}

Figure 10a and 10b shows the optimal layout of the network designed in scenario III for the configuration with a normal set and with a reduced set of connection points, respectively. The ESL distribution is indicated in the figures and is the same as the first distribution in scenario I. Again, optimal AP locations are close to the ECPs and PCPs, in order to reduce the cost. Additionally, they are also located in low-ESL rooms to keep the electric-field values low in high ESL rooms. Both configurations now require 4 APs, slightly more than when only cost is accounted for (scenario II), but much fewer than when only exposure is accounted for (scenario I).

Table 9 compares the characteristics of the networks of scenario III with those of scenario I. Unlike in scenario I (exposure), scenario III (cost + exposure) aims for a reduced installation cost. This cost indeed reduces from $€ 4093$ to $€ 1086$ ( $-73 \%$, normal CP set). The downside here is that field values are higher in scenario III: $E_{50}^{\mathrm{ESL}}$ and $E_{95}^{\mathrm{ESL}}$ increase from 57 to $62 \mathrm{mV} / \mathrm{m}(+9 \%)$ and from 200 to $264(+32 \%)$, respectively, when changing from scenario I to III (normal CP set).

Table 9 also compares the characteristics of the networks of scenario III with those of scenario II. Unlike in scenario II (cost), scenario III (cost + exposure) also aims for a reduced exposure. $E_{50}^{\mathrm{ESL}}$ and $E_{95}^{\mathrm{ESL}}$ decrease from 81 to $62 \mathrm{mV} / \mathrm{m}(-23 \%)$ and from 417 to $264 \mathrm{mV} / \mathrm{m}(-37 \%)$, respectively, when changing from scenario II to III for the configuration with the normal $\mathrm{CP}$ set. For the reduced

Table 9 Overview of network characteristics for scenarios I-|I-|||

\begin{tabular}{cccc}
\hline Scenario & Installation cost $[€]$ & $E_{50}^{\text {ESL }}[\mathrm{mV} / \mathrm{m}]$ & $E_{95}^{\text {ESL }}[\mathrm{mV} / \mathrm{m}]$ \\
\hline I: Normal CP set & 4093 & 57 & 200 \\
II: Normal CP set & 681 & 81 & 417 \\
II: Reduced CP set & 902 & 84 & 373 \\
III: Normal CP set & 1086 & 62 & 264 \\
III: Reduced CP set & 1387 & 58 & 295 \\
REF: Normal CP set & 1510 & 116 & 419 \\
\hline
\end{tabular}


$\mathrm{CP}$ set, $E_{50}^{\mathrm{ESL}}$ and $E_{95}^{\mathrm{ESL}}$ decrease from 84 to $58 \mathrm{mV} / \mathrm{m}$ $(-31 \%)$ and from 373 to $295 \mathrm{mV} / \mathrm{m}(-21 \%)$, respectively. The downside of the trade-off between installation cost and exposure is that in scenario III, the cost is higher than in scenario II: $€ 1086$ vs. $€ 681$ ( $+59 \%)$ for the normal CP set, and $€ 1387$ vs. $€ 902$ ( $+54 \%)$ for the reduced CP set. Reduced CP sets cause higher costs than normal CP sets (€902 vs. $€ 681$ for scenario II and $€ 1387$ vs. $€ 1086$ for scenario III) but have no influence on the field levels, as could be expected (see Table 9).

Scenario III (cost + exposure) is a good trade-off solution between scenario I (exposure) and II (cost): the cost of scenario I is $601 \%$ higher than that of the cost-optimized scenario II, while scenario III leads to a cost increase of only $59 \%$ (normal CP set). Also, the $E_{50}^{\mathrm{ESL}}$ and $E_{95}^{\mathrm{ESL}}$ of scenario II are 49 and $208 \%$ higher than in the exposureoptimized scenario I, respectively, while scenario III leads to $E_{50}^{\mathrm{ESL}}$ and $E_{95}^{\mathrm{ESL}}$ increases of only 9 and $32 \%$, respectively. Table 9 also lists the characteristics of the traditional scenario from [6] (scenario REF), where coverage is provided with three $20 \mathrm{dBm}$ APs, without accounting for exposure or full installation cost: only the number of APs is minimized. It shows that both exposure reduction (scenarios I and III) and cost reduction (scenarios II and III) are efficient in the proposed algorithm. As a summary, in scenario I, the lowest values of $E_{50}^{\mathrm{ESL}}$ and $E_{95}^{\mathrm{ESL}}$ are obtained but this scenario results in the highest installation cost. On the contrary, scenario II has the lowest installation cost but corresponds to the highest exposure values. Scenario III provides trade-off solutions where both installation cost and exposure level are limited. Changing the weights of the fitness functions allows shifting between higher (lower) exposure and the corresponding lower (higher) installation costs.

\subsection{Influence of interference margin (IM)}

When WiFi networks are deployed, interference should be accounted for. The interference margin IM corresponds with an increase of the noise floor due to external interference. Here, IM is assumed at $3 \mathrm{~dB}$, but depending on the level of interference, different values can be assumed. Table 10 shows how interference influences the results for the three scenarios that are considered in this paper. For all scenarios, the coverage percentage for all situation remains $100 \%$. However, when accounting for interference, both the total installation cost and the exposure levels increase, since considering interference leads to higher EIRP levels or to a larger number of APs to maintain the coverage rate. The installation cost, $E_{50}^{\mathrm{ESL}}$, and $E_{95}^{\mathrm{ESL}}$ of scenario I increase from $€ 4093$ to $€ 4114$ (+0.5\%), from 57 to $68 \mathrm{mV} / \mathrm{m}(+16.2 \%)$, and from 200 to $316 \mathrm{mV} / \mathrm{m}$ $(+36.7 \%)$, respectively, when changing including an IM of $3 \mathrm{~dB}$. For scenario II, accounting for interference yields a solution with a cost of $€ 1152$, which is $69 \%$ higher than
Table 10 Network characteristics for all scenarios, with and without considering an interference margin IM of $3 \mathrm{~dB}$

\begin{tabular}{ccccc}
\hline Scenarios & $\begin{array}{c}\text { Coverage rate [\%] } \\
\text { rate [\%] }\end{array}$ & $\begin{array}{c}\text { Installation cost [€] } \\
\text { cost [€] }\end{array}$ & $\begin{array}{c}E^{\mathrm{ESL}}{ }_{50} \\
{[\mathrm{mV} / \mathrm{m}]}\end{array}$ & $\begin{array}{c}E^{\mathrm{ESL}} \\
{[\mathrm{mV} / \mathrm{m}]}\end{array}$ \\
\hline I without IM & 100 & 4093 & 57 & 200 \\
I with IM & 100 & 4114 & 68 & 316 \\
|| without IM & 100 & 680 & 85 & 417 \\
|| with IM & 100 & 1152 & 93 & 529 \\
I| without IM & 100 & 1081 & 61 & 263 \\
I|| with IM & 100 & 1453 & 80 & 353 \\
\hline
\end{tabular}

before $(€ 680)$. In scenario III, we obtain a cost of $€ 1453$, an $E^{\mathrm{ESL}} 50$ of $80 \mathrm{mV} / \mathrm{m}$, and an $E^{\mathrm{ESL}} 95$ of $353 \mathrm{mV} / \mathrm{m}$, compared to $€ 1081,61 \mathrm{mV} / \mathrm{m}$, and $263 \mathrm{mV} / \mathrm{m}$ for scenario III without interference, respectively.

\section{Conclusions}

In this paper, an algorithm is presented for optimal indoor wireless network planning, based on a maximization of coverage and a minimization of the full installation cost (not only access point cost) and the human exposure. Advanced fitness functions are presented, accounting for the total installation cost in a realistic way, and introducing exposure sensitivity levels per room. Three scenarios are defined and simulated. It is shown that a configuration with fewer possible connection points for power and ethernet has a higher installation cost $(+32 \%$ for the considered case). Further, the algorithm successfully reduces exposure levels in rooms that are defined as being sensitive to high electric-field values (average reductions of $50 \%$ and more for the considered case). In a scenario where coverage, cost, and exposure are jointly optimized, a trade-off solution is found where the required coverage is provided, while keeping the total installation cost and the exposure levels limited. Accounting for interference leads to higher installation costs and higher exposure levels. Future research will consist of applying the proposed methods to heterogeneous networks, consisting of WiFi access points and LTE femtocells.

\section{Competing interests}

The authors declare that they have no competing interests.

\section{Author details}

${ }^{1}$ School of Computer Science and Engineering, University Electronic Science and Technology of China, No.2006, Xiyuan Ave, 611731 Chengdu, China.

${ }^{2}$ Ghent University/iMinds, Dept. of Information Technology, Gaston

Crommenlaan 8 box 201, 9050 Gent, Belgium.

Received: 4 September 2014 Accepted: 10 July 2015

Published online: 06 August 2015

\footnotetext{
References

1. A Bahri, S Chamberland, On the wireless local area network design problem with performance guarantees. Comput. Netw. 48(6), 856-866
} (2005) 
2. E Amaldi, A Capone, M Cesana, F Malucelli, F Palazzo, in Vehicular Technology Conference, 2004. VTC 2004-Spring. 2004 IEEE 59th. WLAN coverage planning: optimization models and algorithms, vol. 4, (2004), pp. 2219-2223. doi:10.1109/NETECS.2004.1390668

3. M Deruyck, E Vanhauwaert, D Pareit, B Lannoo, W Joseph, L Martens, WiMAX based monitoring network for a utility company: a case study. Transactions on Emerging Telecommunications Technologies (2012). accepted doi:10.1002/ett.2573

4. G Koutitas, T Samaras, Exposure minimization in indoor wireless networks. Antennas Wireless Propagation Lett. IEEE.

9, 199-202 (2010)

5. D Plets, W Joseph, K Vanhecke, L Martens, in Antennas and Propagation Society International Symposium (APSURSI), 2012 IEEE. A heuristic tool for exposure reduction in indoor wireless networks (Chicago, IL, 2012), pp. 1-2

6. D Plets, W Joseph, K Vanhecke, L Martens, Exposure optimization in indoor wireless networks by heuristic network planning. Prog. Electromagnetics Research-Pier. 139, 445-478 (2013)

7. K Jaffres-Runser, J-M Gorce, S Ubeda, in Vehicular Technology Conference, 2006. VTC-2006 Fall. 2006 IEEE 64th. Multiobjective QoS-oriented planning for indoor wireless LANs (Montreal, Que, 2006), pp. 1-5

8. L Nagy, in Antennas and Propagation, 2007. EUCAP 2007. The Second European Conference On. Indoor radio coverage optimization for WLAN (Edinburgh, 2007), pp. 1-6

9. Z Yun, S Lim, MF Iskander, An integrated method of ray tracing and genetic algorithm for optimizing coverage in indoor wireless networks. Antennas Wireless Propagation Lett. IEEE. 7, 145-148 (2008)

10. N Liu, D Plets, SK Goudos, W Joseph, L Martens, Multi-objective network planning optimization algorithm: human exposure, power consumption, cost, and coverage. Wireless Netw. 21(3), 841-857 (2015)

11. D Plets, N Machtelinckx, K Vanhecke, JV Ooteghem, K Casier, M Pickavet, W Joseph, L Martens, in IEEE International Symposium on Antennas and Propagation and USNC-URSI Radio Science Meeting. Calculation tool for optimal wireless design and minimal installation cost of indoor wireless LANs (Memphis, TN, 2014)

12. JMB OLiveira, S Silva, LM Pessoa, D Coelho, HM Salgado, JCS Castro, in Microwave Photonics (MWP), 2010 IEEE Topical Meeting On. UWB radio over perfluorinated GI-POF for low-cost in-building networks (Montreal, QC 2010), pp. 317-320

13. A Das, A Nkansah, NJ Gomes, IJ Garcia, JC Batchelor, D Wake, Design of low-cost multimode fiber-fed indoor wireless networks. Microwave Theory Tech. IEEE Trans. 54(8), 3426-3432 (2006)

14. R Patra, S Surana, S Nedevschi, E Brewer, in Proceedings of the Second ACM SIGCOMM Workshop on Networked Systems for Developing Regions. NSDR '08. Optimal scheduling and power control for TDMA based point to multipoint wireless networks (ACM New York, NY, USA, 2008), pp. 7-12

15. M Yigitel, O Incel, C Ersoy, Dynamic base station planning with power adaptation for green wireless cellular networks. EURASIP J. Wireless Commun. Netw. 2014(1), 77 (2014)

16. L Suarez, L Nuaymi, J-M Bonnin, An overview and classification of research approaches in green wireless networks. EURASIP J. Wireless Commun. Netw. 2012(1), 142 (2012)

17. Y Lee, K Kim, Y Choi, in Local Computer Networks, 2002. Proceedings. LCN 2002. 27th Annual IEEE Conference On. Optimization of AP placement and channel assignment in wireless LANs (Washington, DC, USA, 2002), pp. 831-836

18. C-K Ting, C-N Lee, H-C Chang, J-S Wu, Wireless heterogeneous transmitter placement using multiobjective variable-length genetic algorithm. Syst. Man Cybernet. Part B: Cybernetics, IEEE Tran. 39(4), 945-958 (2009)

19. L Arya, SC Sharma, in Proceedings of the Second International Conference on Soft Computing for Problem Solving (SocProS 2012), December 28-30, 2012. Advances in Intelligent Systems and Computing, ed. by BV Babu, A Nagar, K Deep, M Pant, JC Bansal, K Ray, and U Gupta. Coverage of indoor WLAN in obstructed environment using particle swarm optimization, vol. 236, (2014), pp. 1583-1594. doi:10.1007/978-81-322-1602-5_157

20. G Mateus, AF Loureiro, R Rodrigues, Optimal network design for wireless local area network. Ann. Oper. Res. 106(1-4), 331-345 (2001)

21. SW Ellingson, in Vehicular Technology Conference, 2005. VTC-2005-Fall. 2005 IEEE 62nd. Antenna design and site planning considerations for MIMO, vol. 3, (2005), pp. 1718-1722
22. T Kikuchi, D Sugita, in Intelligent Green Building and Smart Grid (IGBSG), 2014 International Conference On. A method of an efficient installation process for generic cabling inside customer premises (Taipei, 2014), pp. 1-4

23. P Valberg, T van Deventer, M Repacholi, Workgroup report: base stations and wireless networks-radio frequency (RF) exposures and health consequences. Environ Health Perspect. 115(3), 416-424 (2007)

24. W Joseph, L Verloock, F Goeminne, G Vermeeren, L Martens, Assessment of general public exposure to LTE and RF sources present in an urban environment. Bioelectromagnetics. 31, 576-579 (2010)

25. L Verloock, W Joseph, G Vermeeren, L Martens, Procedure for assessment of general public exposure from WLAN in offices and in wireless sensor network testbed. Health Phys. 98, 628-638 (2010)

26. W Joseph, P Frei, M Roosli, G Thuroczy, P Gajsek, T Trcek, J Bolte, G Vermeeren, E Mohler, P Juhasz, V Finta, L Martens, Comparison of personal radio frequency electromagnetic field exposure in different urban areas across Europe. Environ. Res. 110, 658-663 (2010)

27. CGP Russo, V Vespasiani, A numerical coefficient for evaluation of the environmental impact of electromagnetic fields radiated by base stations for mobile communications. Bioelectromagnetics. 31(8), 613-621 (2010)

28. H Chen, Y Zhu, K Hu, T Ku, RFID network planning using a multi-swarm optimizer. J. Netw. Comput. Appl. 34(3), 888-901 (2011). RFID Technology, Systems, and Applications

29. D Jourdan, OL de Weck, in Vehicular Technology Conference, 2004. VTC 2004-Spring. 2004 IEEE 59th. Layout optimization for a wireless sensor network using a multi-objective genetic algorithm, vol. 5, (2004), pp. 2466-24705. doi:10.1109/NETECS.2004.1391366

30. G Cerri, R De Leo, D Micheli, P Russo, Base-station network planning including environmental impact control. Commun. IEEE Proc. 151(3), 197-203 (2004)

31. M Deruyck, W Joseph, B Lannoo, D Colle, L Martens, Designing energy-efficient wireless access networks: LTE and LTE-Advanced. Internet Comput. IEEE. 17(5), 39-45 (2013)

32. I Vilovic, N Burum, Z Sipus, R Nad, in Applied Electromagnetics and Communications, 2007. ICECom 2007. 19th International Conference On. PSO and ACO algorithms applied to location optimization of the wlan base station (Dubrovnik, 2007), pp. 1-5

33. L Nagy, Global optimization of indoor radio coverage. AUTOMATIKA: časopis za automatiku, mjerenje, elektroniku, računarstvo i komunikacije. 53(1), 69-79 (2012)

34. S-Y Yang, D-W Seo, N-H Myung, in 2010 International Symposium on Antennas and Propagation. Optimal location and number of access points based on ray-tracing and particle swarm optimization (Macau, China, 2010)

35. A Eisenblatter, H-F Geerdes, I Siomina, in World of Wireless, Mobile and Multimedia Networks, 2007. WoWMoM 2007. IEEE International Symposium on A. Integrated access point placement and channel assignment for wireless lans in an indoor office environment (IEEE Espoo, Finland, 2007), pp. $1-10$

36. J Zhang, X Jia, Z Zheng, Y Zhou, Minimizing cost of placement of multiradio and multi-power-level access points with rate adaptation in indoor environment. Wireless Commun. IEEE Trans. 10(7), 2186-2195 (2011)

37. AW Reza, MS Sarker, K Dimyati, A novel integrated mathematical approach of ray-tracing and genetic algorithm for optimizing indoor wireless coverage. Progress Electromagnetics Res. 110, 147-162 (2010)

38. D Plets, W Joseph, K Vanhecke, E Tanghe, L Martens, Coverage prediction and optimization algorithms for indoor environments. EURASIP J. Wireless Commun. Netw. 2012, 123 (2012)

39. D Plets, W Joseph, K Vanhecke, E Tanghe, L Martens, Simple indoor path loss prediction algorithm and validation in living lab setting. Wireless Personal Commun. 68(3), 535-552 (2013) 